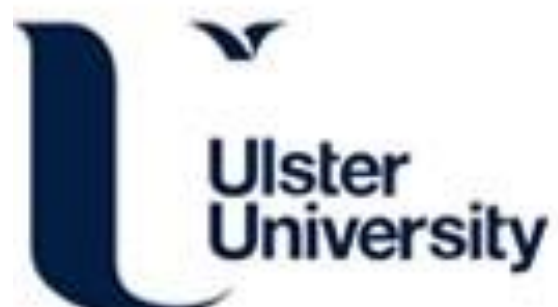

\section{Numerical and experimental validation study of flame extent of a pool fire under the ceiling}

Wang, Y., Vouros, A., Zhang, J., \& Delichatsios, M. A. (2017). Numerical and experimental validation study of flame extent of a pool fire under the ceiling. Journal of Loss Prevention in the Process Industries, 49(Part B), 652-659. https://doi.org/10.1016/j.jlp.2017.04.029

Link to publication record in Ulster University Research Portal

\section{Published in:}

Journal of Loss Prevention in the Process Industries

Publication Status:

Published (in print/issue): 30/09/2017

DOI:

10.1016/j.jlp.2017.04.029

\section{Document Version}

Author Accepted version

\section{General rights}

Copyright for the publications made accessible via Ulster University's Research Portal is retained by the author(s) and / or other copyright owners and it is a condition of accessing these publications that users recognise and abide by the legal requirements associated with these rights.

\section{Take down policy}

The Research Portal is Ulster University's institutional repository that provides access to Ulster's research outputs. Every effort has been made to ensure that content in the Research Portal does not infringe any person's rights, or applicable UK laws. If you discover content in the Research Portal that you believe breaches copyright or violates any law, please contact pure-support@ulster.ac.uk. 


\section{Accepted Manuscript}

Numerical and experimental validation study of flame extent of a pool fire under the ceiling

Yongdong Wang, Alexandros Vouros, Jianping Zhang, Michael A. Delichatsios

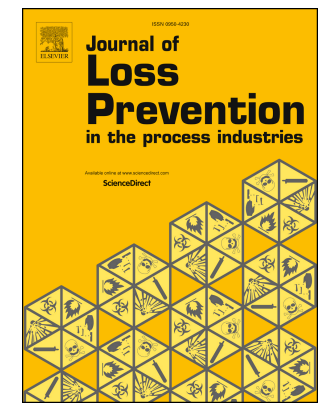

PII:

S0950-4230(17)30410-2

DOI:

10.1016/j.jp.2017.04.029

Reference: JLPP 3495

To appear in: Journal of Loss Prevention in the Process Industries

Received Date: 5 July 2016

Revised Date: 26 April 2017

Accepted Date: 26 April 2017

Please cite this article as: Wang, Y., Vouros, A., Zhang, J., Delichatsios, M.A., Numerical and experimental validation study of flame extent of a pool fire under the ceiling, Journal of Loss Prevention in the Process Industries (2017), doi: 10.1016/j.jp.2017.04.029.

This is a PDF file of an unedited manuscript that has been accepted for publication. As a service to our customers we are providing this early version of the manuscript. The manuscript will undergo copyediting, typesetting, and review of the resulting proof before it is published in its final form. Please note that during the production process errors may be discovered which could affect the content, and all legal disclaimers that apply to the journal pertain. 


\section{Numerical and Experimental Validation Study of Flame Extent of}

\section{A Pool Fire Under the Ceiling}

Yongdong Wang ${ }^{\mathrm{a}, \mathrm{b}}$, Alexandros Vouros ${ }^{\mathrm{c}}$, Jianping Zhang ${ }^{\mathrm{b}, *}$, Michael A Delichatsios ${ }^{\mathrm{b}}$

${ }^{\text {a }}$ School of Highway, Chang' an University, Xi'an, Shaanxi 710064, China

${ }^{\mathrm{b}}$ FireSERT, School of Built Environment and Built Environment Research Institute, Ulster University, Newtownabbey, BT37 0QB, UK

${ }^{c}$ Civil Engineering Department, University of Patras, 26504, Patras, Greece

* Corresponding author:

Jianping Zhang

Tel.: +44 (0)2890366460

Email: j.zhang@uslter.ac.uk

Postal address: FireSERT, School of the Built Environment, Ulster University,

Newtownabbey, BT37 0QB, UK 


\section{Abstract}

The purpose of this work is to establish dimensionless correlations for the flame extent under a ceiling that can be used for large-scale calculations of radiative heat fluxes for which numerical simulations may be prohibitive. Towards this objective, this paper presents a numerical study of the flame height in an open pool fire and the subsequent flame extent under the ceiling. The stoichiometric mixture fraction is used to define the continuous flame height which also coincides with the maximum mean temperature along the centerline of the fire. The size of the pool fire is $0.1 \mathrm{~m} \times 0.1 \mathrm{~m}$ having heat release rates (HRRs) from 2 to 100 $\mathrm{kW}$ for two ceiling heights of 30 and $50 \mathrm{~cm}$. The predicted free flame height and horizontal flame extent are compared to existing correlations and experimental data in the literature. It is found that the predicted continuous flame height is about three fifths that of the experimental mean flame height reported in the literature. The predicted horizontal flame extent also agrees well with existing experimental correlations, although some difference may indicate that the relation between the mean and continuous flame heights derived for an open free pool fire may no longer apply due to the presence of the ceiling which affects air entrainment and the turbulence of the ceiling flame jet.

Keywords: pool fire, ceiling, flame extent, FDS, stoichiometric mixture fraction 


\section{Introduction}

Despite the substantial research on fire dynamics, one of the most important issues for fires that are developing under ceilings is the estimation of the horizontal distance at which the flame extents at the lower surface of the ceiling. A number of studies have been published; however, it was shown in Ding and Quintiere (2012) that various expressions can be applied to correlate the experimental results in the literature for a range of geometrical and flow configurations (You and Faeth, 1979; Babrauskas, 1980; Beyler, 1986; Gross, 1989; Heskestad and Hamada, 1993).

The most important parameters of this particular problem is the chemical power or the heat release rate $(\mathrm{HRR})$ of the fire, $\dot{Q}$, the diameter of the fire source, or the equivalent diameter for rectangular sources, $\mathrm{D}$, and the ratio of the vertical distance at which the ceiling is imposed -often mentioned as ceiling height- to the diameter of the source H/D. Another important aspect is the characterization of the ceiling as confining or non-confining, which is applied in cases for which the length of the ceiling is small and additional walls are considered at the side boundaries or large, such as in fires developing inside tunnels, metro stations etc.

For non-confining ceilings, two major correlations were proposed, producing however significantly diverging results (You and Faeth, 1979; Heskestad and Hamada, 1993; Karlsson and Quintiere, 1999; Drysdale, 2011). You and Faeth (1979) showed that the flame extent under the ceiling is almost half that of the flame length in open-in-air conditions subtracting the ceiling height, whereas Heskestad and Hamada (1993) indicated that the flame extent is equal to the difference between the open-in-air flame length and the ceiling height. Karlsson and Quintiere (1999) suggested that both relations are valid: the first one can be applied to small-scale experiments with small HRRs (Babrauskas, 1980), while the second one to fires with large HRRs (Heskestad and Hamada, 1993). 
Recently, Ding and Quintiere (2012) developed an analytical model to define a single valid correlation for the flame extent under the ceiling, independent of the flow and geometrical parameters. In order to validate their model, they gathered all the available measurements in the literature (You and Faeth, 1979; McCaffrey, 1979; Heskestad and Hamada, 1993; Gross, 1989; McGrattan et al., 2013). Although the resulted model is considered a plausible contribution to the problem of fires under ceiling, this work actually demonstrated large variations of the imposed conditions of the various experiments. In particular, different optical methods including visual observations, photos and videos have been applied, so that it is finally questioned if the results are really compatible with each other and if all these results can be used to validate the model and the additional concepts presented by the authors. More recently, Lattimer et al. (2014) summarized several studies that have been conducted for heat fluxes and flame lengths from fires under ceilings whereas Gao et al. (2015) examined the detailed flame shape and flame length under the ceiling by comparing experiments where fires are in the open space, flush with a wall without ceiling, at the longitudinal centerline of a channel and flush with the sidewall of a channel.

It should be noted that for the majority of the correlations included in the above studies, the flame extent under the ceiling is estimated as a function of the flame height in open-in-air conditions, for which a number of well-established correlations exist. Although it is believed that this length denotes the reaction zone, it has to be noted that since it is taken by visual observations or optical methods, it can be assumed to be related to the luminous and non-luminous parts of the flame which depend mainly on the production of soot rather than the reaction products. A more accurate notion of this length would involve the stoichiometric value of mixture fraction, which theoretically defines the reaction zone, and in a second step the investigation of the relationship between the optically recorded length and that corresponding to the reaction zone. As the reaction zone can be now defined by advanced 
computational tools, new correlations can be produced by taking into account this length as the characteristic length of the flame.

In the present paper, numerical simulations using a validated computational tool, fire dynamics simulator (FDS, version 6) (McGrattan et al., 2013), are used to produce a new correlation for the horizontal extent of impinging flames under a ceiling. To define this length and also, the flame length in open-in-air conditions, the stoichiometric value of mixture fraction is used.

The paper is structured as follows: firstly, a brief description of the numerical model is given. The results in open-in-air conditions are used to validate the model, considering in particular the stream-wise distributions of velocity and temperature fields at the central axis of the flame. Subsequently, the results for a range of HRRs under two ceiling heights are presented. These results are used to produce the new correlation based on the stoichiometric values of mixture fraction. Finally, direct comparisons of the proposed correlation with earlier experimental measurements available in the literature are presented, denoting clear differences that can be however attributed to the estimation of the characteristic lengths and the different techniques applied in the various experiments.

\section{Numerical Details}

Fire Dynamics Simulator (FDS) version 6 (McGrattan et al., 2013) is a Large Eddy Simulation (LES) model, based on the low-Mach approximation. It solves directly the equations of mass and momentum transport, while the flow divergence is used as a surrogate for the enthalpy transport equation. Radiation transport is calculated based on the gray gas approach and is solved in the same grid used by the flow solver. Combustion modeling is based on the eddy dissipation concept, for which the level of mixing and the change of the species concentration due to chemical reactions is applied in a time-splitting technique. This 
combustion model in FDS6 implies that the mixture fraction is no longer a conserved variable as was in FDS5 and as a result it can only be determined from the balance of carbon atoms through post-processing.

\subsection{McCaffrey's Case}

The experimental data by McCaffrey using a $30 \mathrm{~cm} \times 30 \mathrm{~cm}$ methane burner (McCaffrey, 1979 ) is firstly simulated to examine the accuracy of FDS6 for predicting the distribution of temperature and velocity, which is essential in the prediction of the flame height in open conditions as well as the flame extent under the ceiling. A lot of work has been carried out in the past on validation of FDS6 for pool fires (McGrattan et al., 2013) but we think it is important to include this case here because we want to demonstrate and validate the concept that the stoichiometric mixture fraction can be used for representing the continuous flame height.

McCaffrey (1979) performed detailed measurements and dimensional analysis of temperature and axial velocity and found that the fire can be divided into three regions: continuous, intermittent and plume regions with the boundaries of these regions defined based on a normalized height, $\mathrm{z} / \dot{Q}^{2 / 5}$. The continuous flame height $\left(\mathrm{h}_{\mathrm{c}}\right)$ was defined as $\mathrm{z} / \mathrm{Q}^{2 / 5}=0.08$, whereas the intermittent flame height $\left(\mathrm{h}_{\text {inter }}\right)$ as $\mathrm{z} / \mathrm{Q}^{2 / 5}=0.2$.

The computational domain is $1.2 \mathrm{~m} \times 1.2 \mathrm{~m} \times 2.0 \mathrm{~m}$ and the grid size is $1 \mathrm{~cm}$ in all directions, resulting in a total of 2.88 million control volumes $(120 \mathrm{X} \times 120 \mathrm{Y} \times 200 \mathrm{Z})$. The domain size and grid size were determined based on sensitivity studies, which showed that the present setup produces results that no longer change with a further reduction in the grid size or an increase in the domain size. Open boundary conditions are applied at all domain boundaries except for the floor. The fire source issuing methane $(30 \mathrm{~cm} \times 30 \mathrm{~cm})$ was located at the center of the floor. Heat release rate per unit area (HRRPUA) is specified to produce the required HRR. 


\subsection{Open Pool Fire}

For the open fire case, the computational domain $(0.4 \mathrm{~m} \times 0.4 \mathrm{~m} \times 1.0 \mathrm{~m})$ consists of 1.28 million control volumes $(80 \mathrm{X} \times 80 \mathrm{Y} \times 200 \mathrm{Z})$ with a uniform grid size of $0.5 \mathrm{~cm}$. The fire source issuing propane $(0.1 \mathrm{~m} \times 0.1 \mathrm{~m})$ is located at the center and $1 \mathrm{~cm}$ above the floor. The smoke yield is assumed to be $0.01 \mathrm{~g} / \mathrm{g}$. Heat release rate is varied from 2 to $100 \mathrm{~kW}$. The total calculation time is $10 \mathrm{~s}$ and final results are the average over the last 5 seconds of the simulations (the predicted HRR history shows that the fire becomes steady after 2s).

\subsection{Pool Fire under Ceiling}

For the ceiling fire case, two ceiling heights are examined, namely 30 and $50 \mathrm{~cm}$. The dimensions in the $\mathrm{X}$ and $\mathrm{Y}$ directions are $2.0 \mathrm{~m} \times 2.0 \mathrm{~m}$. A uniform grid size of $1 \mathrm{~cm}$ is used. Grid sensitivity studies for the open pool fire case indicate that the predictions using grid sizes of 0.5 and $1 \mathrm{~cm}$ are very similar. The same burner size as in the open pool fire case is used. The total calculation time is 30 seconds with the final results averaged over the last 10 seconds.

\section{Results and Discussions}

\subsection{McCaffrey's Case}

Figure 1 shows a comparison of predicted and experimental temperature rise and axial velocity along the centerline for a HRR of $21.7 \mathrm{~kW}$. The predicted temperature is in very good agreement with the experimental data except for slight under-prediction near the burner surface. It is possible that the thermocouples near the burner surface were heated by flame radiation, resulting in higher temperature reading than the surrounding gas temperature. The predicted velocity also agrees well with the measurement, particularly in the intermittent and 
plume regions.

Figure 2 displays the predicted normalized centerline temperature rise and vertical velocity for all four HRRs $(14.4,21.7,33.0$ and $44.9 \mathrm{~kW})$ along with the correlation given by McCaffrey (1979). It is noted that the predicted normalized temperature rise and velocity in the continuous and plume regions are nearly independent of HRR and also agree with the correlations (McCaffrey, 1979). There is, however, considerable difference in the region close to the burner surface, where a decrease of temperature rise with an increase in HRR is observed, owing to an increase in the fuel mass fraction with an increase in the HRR.

Figure 3 shows the 2D contour of the predicted average mixture fraction near the fire source for the case of $21.7 \mathrm{~kW}$. As mentioned earlier, the stoichiometric value of mixture fraction given by Eq. 1 is used to define the continuous flame height.

$$
Z_{f}=\frac{Y_{O_{2}}^{\infty}}{s Y_{F}^{I}+Y_{O_{2}}^{\infty}}
$$

where $Y_{F}^{I}$ is the fuel concentration at the inlet and typically one and s is the stoichiometric ratio between fuel and oxygen. In this work, methane and propane are used, which have stoichiometric mixture fraction values of 0.0544 and 0.0595 respectively.

The continuous flame height, $h_{f c}$, can then be determined as the highest point where mixture fraction is equal to 0.0544 , which is approximately $0.263 \mathrm{~m}$. This value agrees well with the one from McCaffrey's correlation: $\mathrm{h}_{\mathrm{fc}}=0.08 \dot{\mathrm{Q}}^{2 / 5}$, which, for a fire source of $21.7 \mathrm{~kW}$, is $0.274 \mathrm{~m}$. Because most of flame height correlations are defined based on the mean (visual) flame height, $h_{f m}$, we use in this work the relation by Shintani et al. (2014) that the continuous flame height is $60 \%$ that of the mean flame height. For the present case, we have $h_{f m}=\frac{h_{f c}}{0.6}=0.438 \mathrm{~m}$, which agrees with the one calculated from Heskestad's correlation (1983): $h_{f m}=0.235 \dot{Q}^{2 / 5}-1.02 D$, having a flame height of $0.459 \mathrm{~m}$. 


\subsection{Open Pool Fire}

We apply the same procedure as shown in Fig. 3 for all the open fire cases $(10 \mathrm{~cm} \times 10 \mathrm{~cm})$. Figure 4 plots the predicted continuous flame height against HRR, along with the one calculated using Heskestad's relation multiplied by 0.6 . There is a reasonably good agreement between the two sets of data, although the predictions tend to be slightly lower than the ones from the correlation.

Further validation of the present results is shown in Fig. 5, where the normalized continuous flame height, $H_{f c} / D$, is plotted as a function of a dimensionless HRR, $Q_{D}^{*}$ $\left(=\frac{Q}{C_{p} \rho_{\infty} T_{\infty} g^{\frac{1}{2} D^{\frac{5}{2}}}}\right)$ along with the correlation proposed by Hasemi and Tokunaga (1984) as shown in Eq. 2. This correlation uses slightly different expressions for buoyancy-dominated (small $\left.Q_{D}^{*}\right)$ or jet like fire (large $Q_{D}^{*}$ ) regimes

$$
h_{f c} / D=1.8 Q_{D}^{* n}
$$

where: $n=\frac{2}{3}$ for $\left(Q_{D}^{*} \leq 1\right)$ or $n=\frac{2}{5}$ for $\left(Q_{D}^{*}>1\right)$

Note that the definition of this dimensionless HRR, $Q_{D}^{*}$, includes the effect of the burner diameter. The prediction agrees well with the correlation. It can also be seen that for the present study the majority of the data are in the jet-like fire regime, i.e., $Q_{D}^{*}>1$.

The result in Figs. 4 and 5, along with those in Figs. 1 and 2, verify that (i) FDS is capable of predicting accurately the distribution of temperature and velocity and (ii) the stoichiometric mixture fraction can be used to represent the continuous flame height.

\subsection{Pool Fire under Ceiling}

For a pool fire under the ceiling, the flame will spread along the ceiling after it reaches the ceiling. The horizontal flame extent (radius) along the ceiling is an important factor in 
considering the ignition of adjacent objects by radiation. Figure 6 shows the diagram of a flame spreading under the ceiling in a ceiling fire, where $h_{c c}$ is the cut-off continuous flame height in the case where the continuous flame height in open conditions $\left(h_{f c}\right)$ is larger than the ceiling height, $H$, and $h_{h c}$ is the horizontal continuous flame length (extent) under the ceiling.

For most of the cases studied in this work, the flame has reached the ceiling. For the few cases where the flame is below the ceiling, it was found that the calculated flame height is systematically lower than that in open conditions as shown in Fig. 7, indicating that the ceiling has an important impact on increasing air entrainment and thus combustion near the fuel surface.

Figure 8 shows the 2D contour of the predicted average mixture fraction under the ceiling for $\mathrm{HRR}=50 \mathrm{~kW}$ and $\mathrm{H}=0.3 \mathrm{~m}$. The data is nearly axisymmetric as expected, although there are fluctuations due to the turbulent nature of the flame. The final flame extent presented in the next sections is taken as the average of those in all four directions, i.e., $\mathrm{X}+, \mathrm{X}-, \mathrm{Y}+$ and Y-.

Figure 9a presents the predicted horizontal flame extent against the cut-off continuous flame height both normalized by the ceiling height for both ceiling heights. The data confirms that the relation between the two dimensionless flame heights is independent of the ceiling height. The relation from the best fit is

$$
\frac{h_{h c}}{H}=1.13\left(\frac{h_{c c}}{H}\right)^{0.78}
$$

In general, it would be expected that

$$
\frac{h_{h c}}{H}=\text { Function }\left(\frac{h_{c c}}{H}, \frac{D}{H}\right)
$$

However the simulation does not show the diameter effect. We believe that this is so because the diameter effect is included in the free flame height used to determine $h_{c c}=H_{f c}-H$ 
(see Fig. 6). We also expect that special treatment is needed if the ceiling clearance is equal to or less than the pool diameter.

Gross (1989) measured the continuous flame height using both thermocouples and an infrared camera, so we can compare directly the experimental data with the present correlation as shown in Fig. 9b. The experimental data in Fig. 9b are reported as (i) directly observed ceiling flame extensions (visual observation), (ii) instantaneous exposure $35 \mathrm{~mm}$ transparencies, (iii) extended exposure $35 \mathrm{~mm}$ transparencies and (iv) video recordings. The present correlation is in the best agreement with the experimental flame extent measured using extended expose transparencies. It is worthwhile to note that the experimental data is in a relatively narrower range compared to the present calculation.

Figure 10 presents the predicted horizontal flame extent normalized by the diameter of the burner, $h_{h} / D$, against the cut-off continuous flame height normalized by $\mathrm{D}, h_{c} / D$, along with the correlation by You and Faeth (1979). It can be observed that the calculated normalized flame extent, similar for both ceiling heights, is significantly higher than the correlation. Because the correlation in You and Faeth (1979) was deduced based on the mean flame height, we also include in this figure the horizontal flame extent and cut-off height modified for the mean flame height by using the relation between the mean and continuous flame heights deduced for open conditions that the continuous flame height is $60 \%$ that of the mean flame height. However, whilst the data shift to the left the trends are similar and the predictions are still considerably higher than the correlation, indicating that the effect of HRR needs to be taken into consideration in the comparison.

Ding and Quintiere (2012) correlated the horizontal continuous/mean flame length under a horizontal ceiling: $\frac{h_{h}}{D}$, with a dimensionless HRR $Q_{D}^{*}=\frac{Q}{C_{p} \rho_{\infty} T_{\infty} g^{\frac{1}{2} D^{\frac{5}{2}}}}$ as shown in Fig. 11 for the present results. The flame extent deduced using the continuous flame height is considerably lower than the correlation, whereas the one using the mean flame height 
correlates much better with the relation in (Ding and Quintiere, 2012). This result indicates that the use of the stoichiometric mixture will underestimate the mean flame height. The relation between the mean and continuous flame heights for open fires may also no longer be applicable in fires under the ceiling due to the presence of the ceiling, which will render the flame less turbulent. Furthermore, the numerical results also show that the flame extent depends on the height of the ceiling, which was not included in the correlation in (Ding and Quintiere, 2012).

Yokobayashi et al. (1996) proposed a new formulation for the dimensionless HRR, $Q_{D H}^{*}$, including the effect of both the burner diameter and ceiling height.

$$
\left(h_{h}+H\right) / H=2.58 Q_{D H}^{*}{ }^{2 / 5}
$$

where: $Q_{D H}^{*}=\frac{Q}{C_{p} \rho_{\infty}{ }_{\infty} g^{1 / 2} D H^{3 / 2}}$

Figure 12 shows a comparison of the present data and the correlation in (Yokobayashi et al., 1996). Inclusion of the ceiling height improves considerably the agreement between the prediction and correlation. Another very important observation of the results is that the data from the two ceiling heights collapse highlighting the importance of the ceiling height in horizontal flame extent correlations. The flame extent calculated from the mean flame height is in closer agreement with the correlation.

\section{Conclusions}

The paper presents a numerical study of flame height resulting from a small pool fire and subsequently the horizontal flame extent under the ceiling. Simulations were performed using FDS for various heat release rates and the predicted flame height and horizontal flame extent are compared to existing correlations and experimental data. The objective of this work is to establish dimensionless correlations for the flame extent under a ceiling to be used for large scale calculations of radiative heat fluxes for which numerical simulations may be prohibitive. 
Towards this objective, the main conclusions of this work are:

- FDS is capable of predicting well the distribution of temperature and velocity as well as the flame height in free fire plumes. The stoichiometric mixture fraction is shown to define the continuous visual flame height;

- The stoichiometric mixture fraction has been also used to predict the radial extent of the flames under a ceiling.

- Comparison of the simulations with experimental extent of flames is within the uncertainties related to the definition of visual continuous and mean flame height.

- The correlation of simulations given by Eq. $3 \mathrm{a}$ is proposed as more appropriate for the extent of the flames as it includes the diameter effect and the heat release rate through the free flame height.

\section{Acknowledgements}

Dr Wang would like to acknowledge the financial support from Chinese Scholarship Council under the State Scholarship Fund 2013 and Hellenic General Secretariat for Research \& Technology under grant ERC-12 (PRESCIENT) of the Operational Program "Education and lifelong learning", co-funded by the European Union (European Social Fund) and national resources.

\section{References}

Babrauskas, V., 1980. Flame lengths under ceilings. Fire Mater. 4 (3), 119-126.

Beyler, C.L., 1986. Fire plumes and ceiling jets. Fire Saf. J. 11 (1-2), 53-75.

Ding, H., Quintiere, J., 2012. An integral model for turbulent flame radial lengths under a ceiling. Fire Saf. J. 52, 25-33.

Drysdale, D., 2011, An Introduction to Fire Dynamics. Third Edition, Wiley. 
Gao, Z., Ji, J., Wan, H., Li, K., Sun, J., 2015. An investigation of the detailed flame shape and flame length under the ceiling of a channel. Proc. Combust. Inst. 35 (3), 2657-2664.

Gross, D., 1989. Measurements of flame lengths under ceilings, Fire Saf. J. 15 (1), 31-44.

Hasemi, Y., Tokunaga, T., 1984. Flame geometry effects on the buoyant plumes from turbulent diffusion flame. Fire Sci. Technol. 4 (1), 15-26.

Heskestad, G., 1983. Luminous heights of turbulent diffusion flames. Fire Saf. J. 5 (2), 103-108.

Heskestad, G., Hamada, T., 1993. Ceiling jets of strong fire plumes. Fire Saf. J. 21 (1), 69-82.

Karlsson, J., Quintiere, J., 1999. Enclosure Fire Dynamics. CRC Press.

Lattimer, B.Y., Mealy, C., Beitel, J., 2013. Heat fluxes and flame lengths from fires under ceilings. Fire Technol. 49 (2), 269-291.

McCaffrey, B.J., 1979. Purely buoyant diffusion flames: some experimental results. Final report. Washington (DC), National Bureau of Standards, US Department of Commerce. Available from: NTIS, Springfield, VA. NBSIR 79-1910.

McGrattan, K., Hostikka, S., McDermott, R., Floyd, J., Weinschenk, C., Overholt, K., 2013. Fire dynamics simulator: User's guide. NIST Special Publication 1019, Sixth Edition.

Shintani, Y., Nagaoka, T., Deguchi, Y., Ido, K., Harada, K., 2014. Simple method to predict downward heat flux from flame to floor. Fire Sci. Technol. 33 (1), 17-34.

Yokobayashi Y., Hasemi Y., Wakamatsu T., Wakamatsu T., Heating mechanism of flat ceiling exposed to localized fire - an introduction to the fire safety design of building structures exposed to localized fire. Journal of Structure Construction Engineering, AIJ, (484):149-156(1996) (in Japanese).

You, H.Z., Faeth, G.M., 1979. Ceiling heat transfer during fire plume and fire impingement. Fire Mater. 3 (3), 140-147. 


\section{Figure Captions}

Figure 1. Comparison of predicted and measured (McCaffrey, 1979) (a) temperature rise and (b) axial velocity along the centerline $\mathrm{HRR}=21.7 \mathrm{~kW}$.

Figure 2. Comparison of predicted and a) temperature rise and (b) axial velocity along the centerline at different heat release rates (HRRs) along with McCaffrey's correlation (McCaffrey, 1979).

Figure 3. Predicted 2D contours of average mixture fraction near the fire source for HRR= $21.7 \mathrm{~kW}$.

Figure 4. Comparison of predicted continuous flame height and that calculated by Heskestad and Hamada's correlation (Heskestad and Hamada, 1993) multiplied by 0.6 at different HRRs.

Figure 5. Comparison of predicted dimensionless flame height, $h_{f c} / D$, against dimensionless HRR, $\dot{Q}_{D}^{*}$, and Hasemi and Tokunaga's correlation (Hasemi and Tokunaga, 1984).

Figure 6. Diagram of flame height and flame extent under the ceiling.

Figure 7. Comparison of predicted continuous flame height in open conditions and under the ceiling.

Figure 8. Predicted 2D counts of average mixture fraction in under the ceiling for the case: $\mathrm{HRR}=50 \mathrm{~kW}$ and $\mathrm{H}=0.3 \mathrm{~m}$. The minimum value in the figure corresponds to the stoichiometric mixture fraction of propane, 0.0595 .

Figure 9. (a) Predicted normalized continuous horizontal flame extent, $h_{h c} / H$, against normalized continuous cut-off height, $h_{c c} / H, \quad$ and the present correlation (Eq. 4a) and (b) comparison of the present correlation with experimental data in (Gross, 1989).

Figure 10. Comparison of predicted normalized horizontal flame length, $h_{h} / D$, against normalized cut-off flame height, $h_{c} / D$, using both mean and continuous flame heights for 
both ceiling heights. The correlation (You and Faeth, 1979) is calculated based on the mean flame height.

Figure 11. Comparison of predicted normalized horizontal flame length, $h_{h} / D$, against normalized heat release rate, $\dot{Q}_{D}^{*}$, using both mean and continuous flame height for both ceiling heights. The correlation (Ding and Quintiere, 2012) is calculated based on the mean flame height.

Figure 12. Comparison of predicted normalized horizontal flame length, $\left(h_{h}+H\right) / H$, against normalized heat release rate, $\dot{Q}_{D H}^{*}$, using both mean and continuous flame height for both ceiling heights. The correlation (Yokobayashi et al., 1996) is calculated based on the mean flame height. 


\section{Figures}

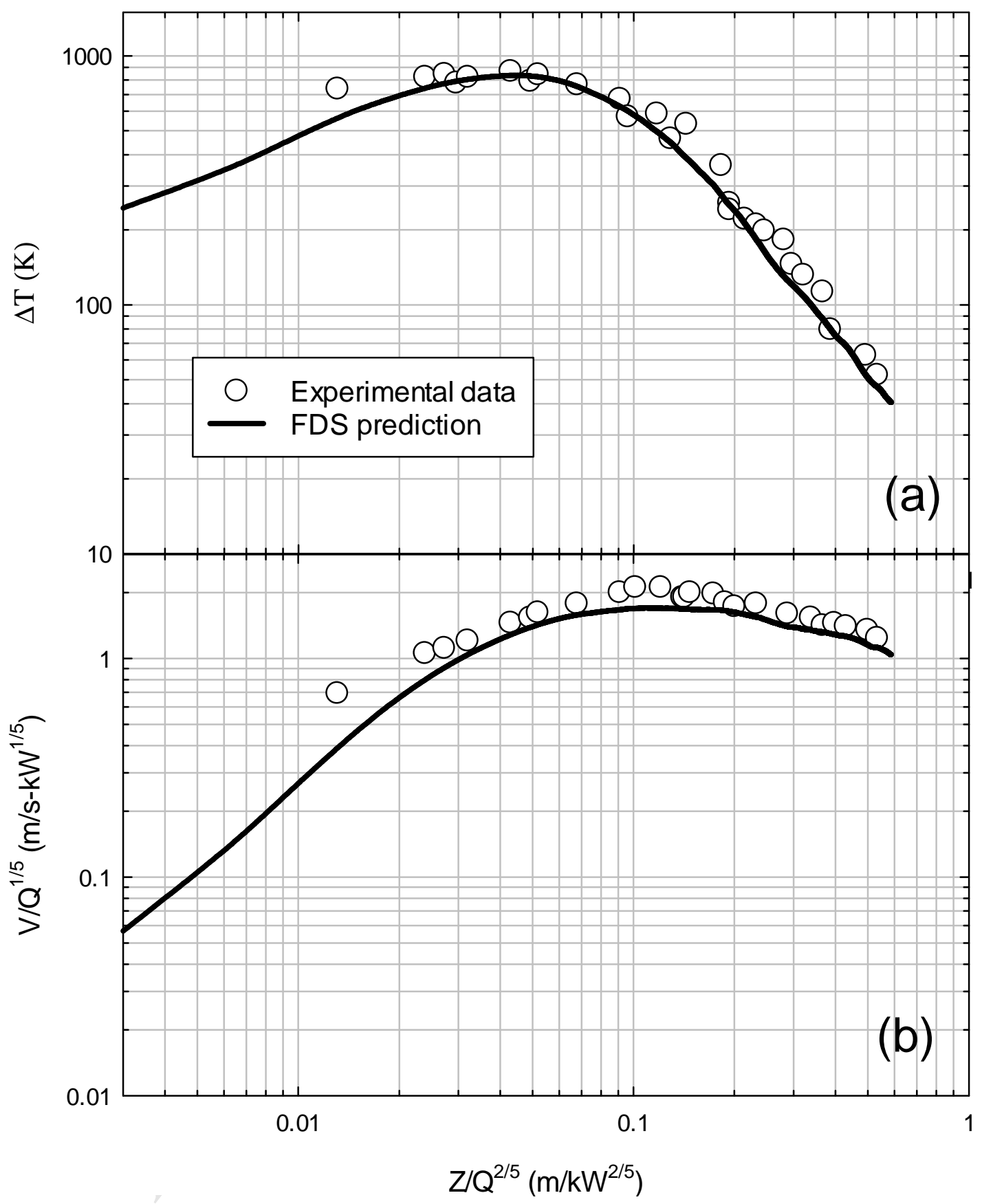

Figure 1. Comparison of predicted and measured (McCaffrey, 1979) (a) temperature rise and (b) axial velocity along the centerline $\mathrm{HRR}=21.7 \mathrm{~kW}$. 


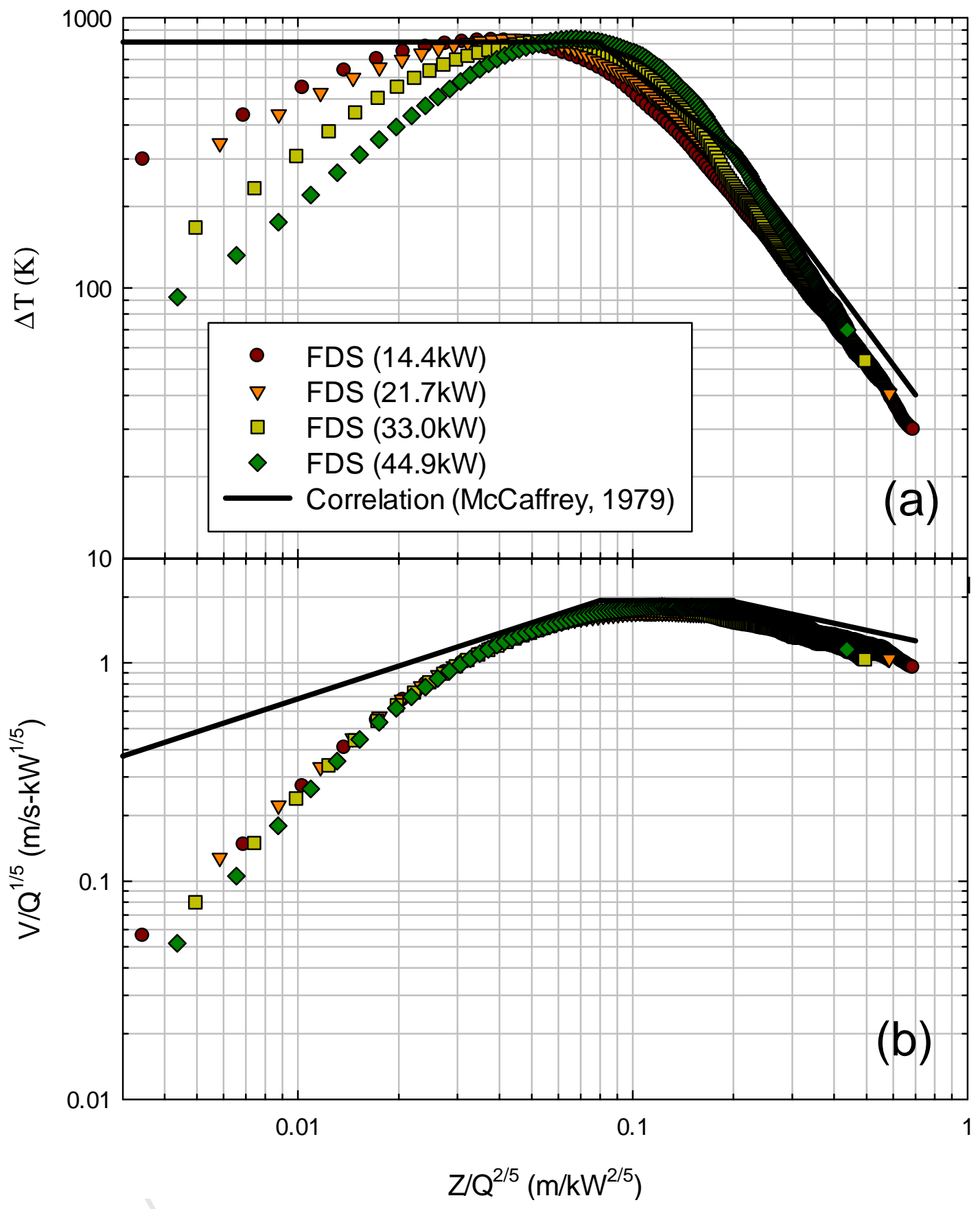

Figure 2. Comparison of predicted and a) temperature rise and (b) axial velocity along the centerline at different heat release rates (HRRs) along with McCaffrey's correlation (McCaffrey, 1979). 


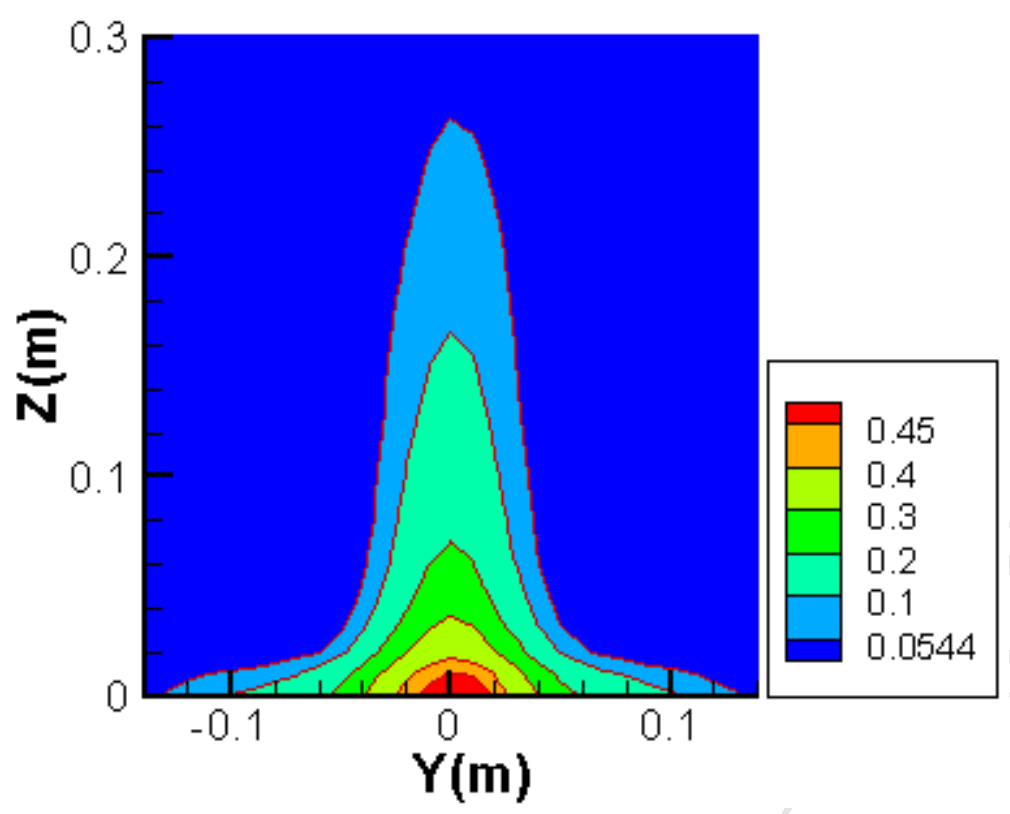

Figure 3. Predicted $2 \mathrm{D}$ contours of average mixture fraction near the fire source for HRR= $21.7 \mathrm{~kW}$ 


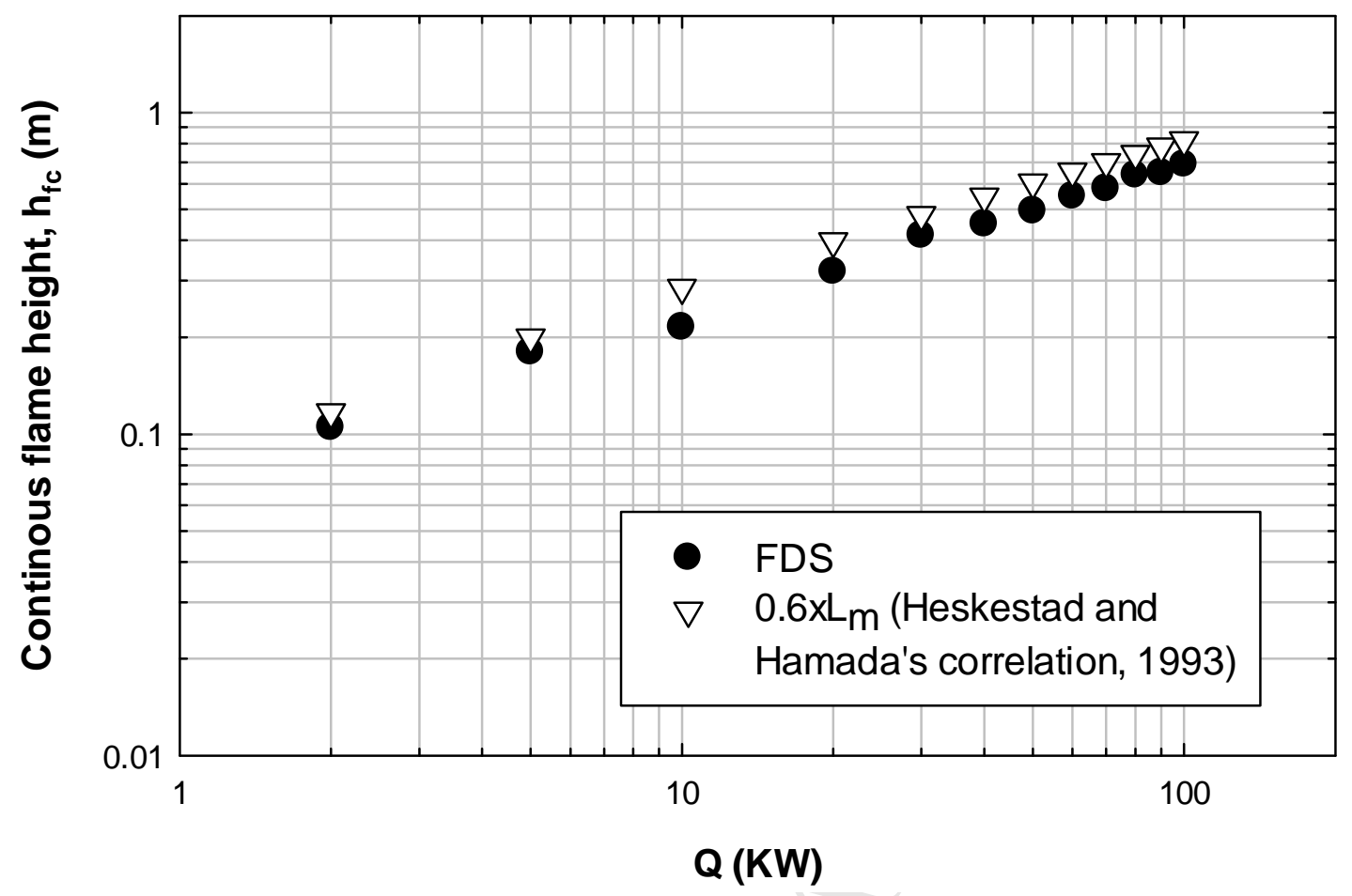

Figure 4. Comparison of predicted continuous flame height and that calculated by Heskestad and Hamada's correlation (Heskestad and Hamada, 1993) multiplied by 0.6 at different HRRs. 


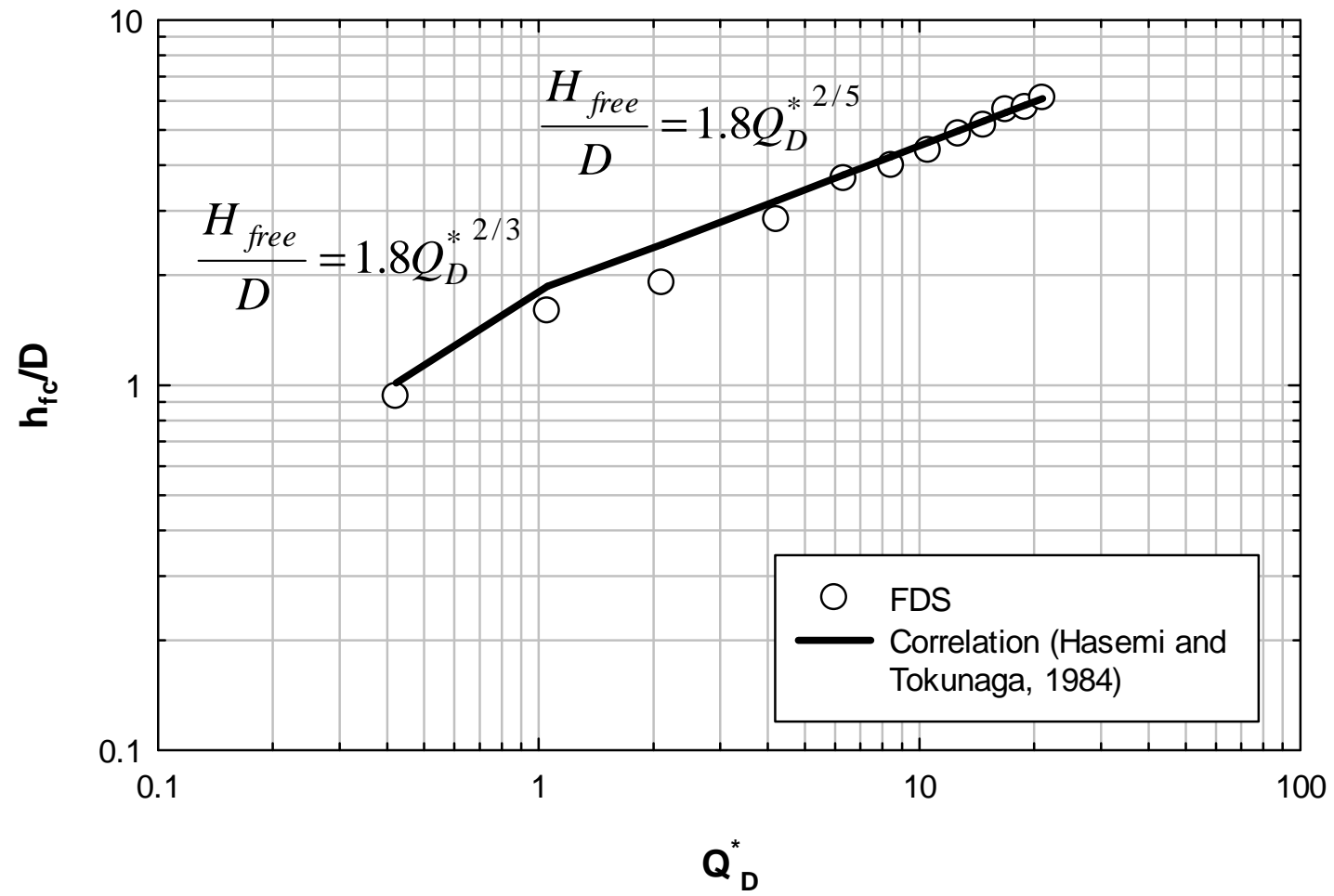

Figure 5. Comparison of predicted dimensionless flame height, $h_{f c} / D$, against dimensionless HRR, $\dot{Q}_{D}^{*}$, and Hasemi and Tokunaga's correlation (Hasemi and Tokunaga, 1984). 


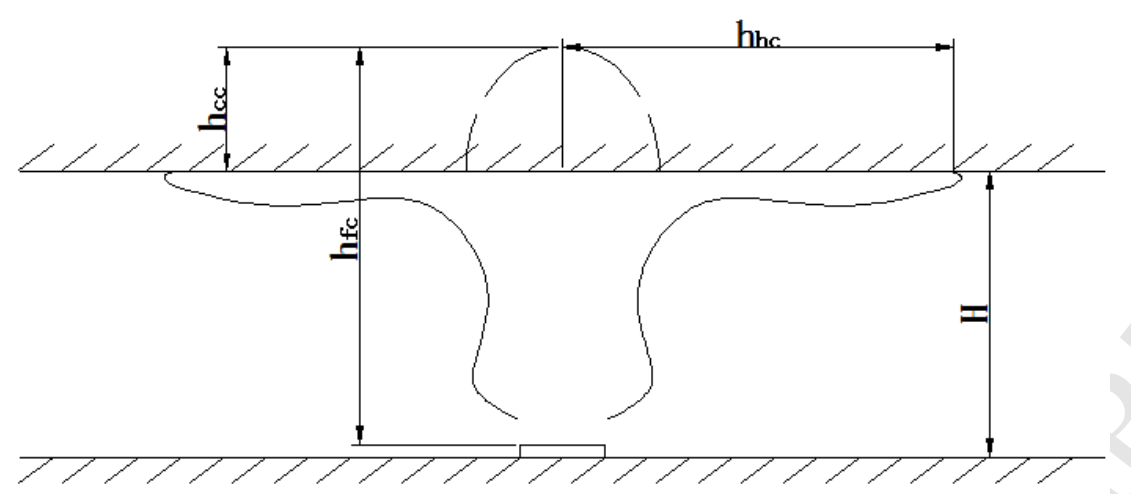

Figure 6. Diagram of flame height and flame extent under the ceiling. 


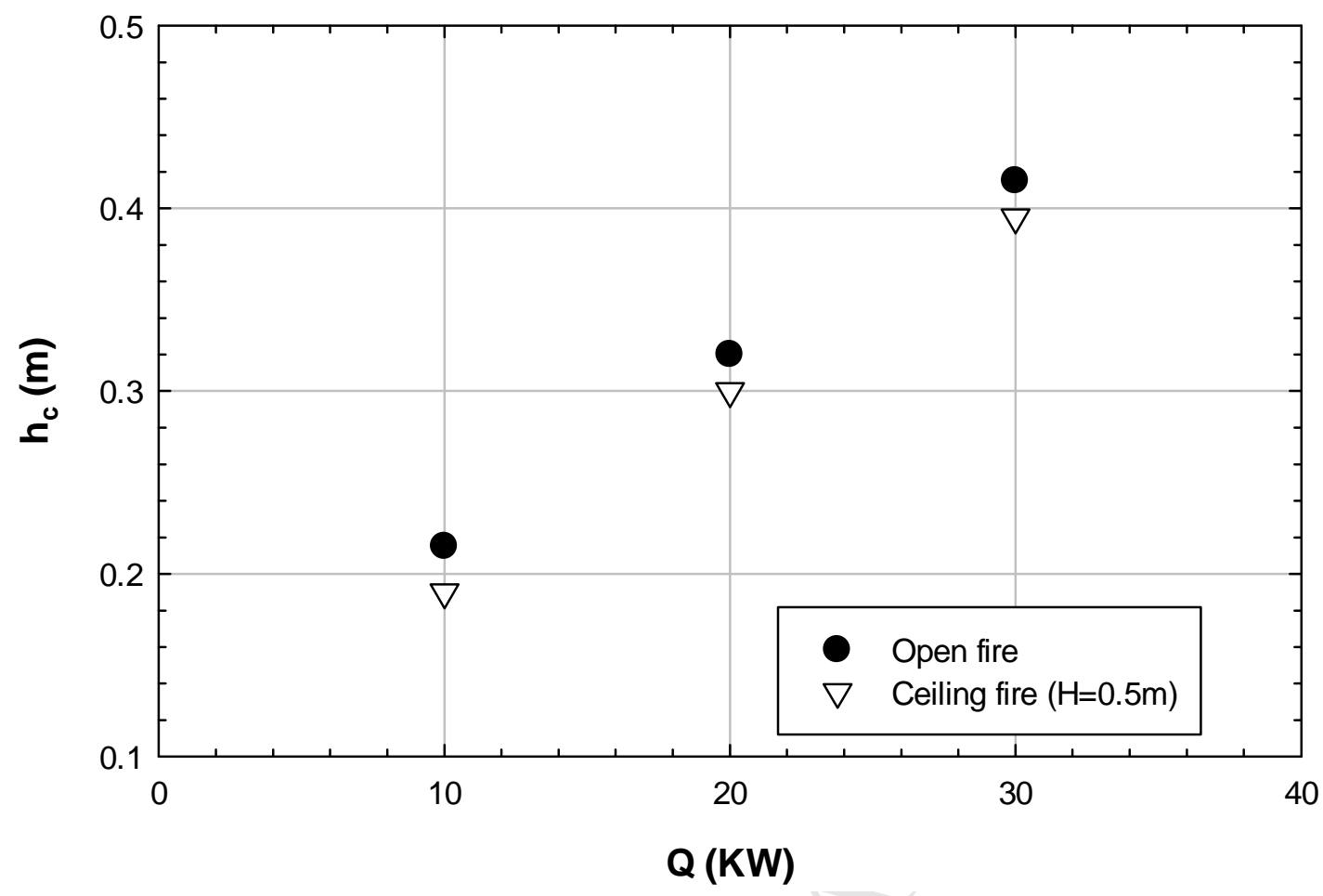

Figure 7. Comparison of predicted continuous flame height in open conditions and under the ceiling. 


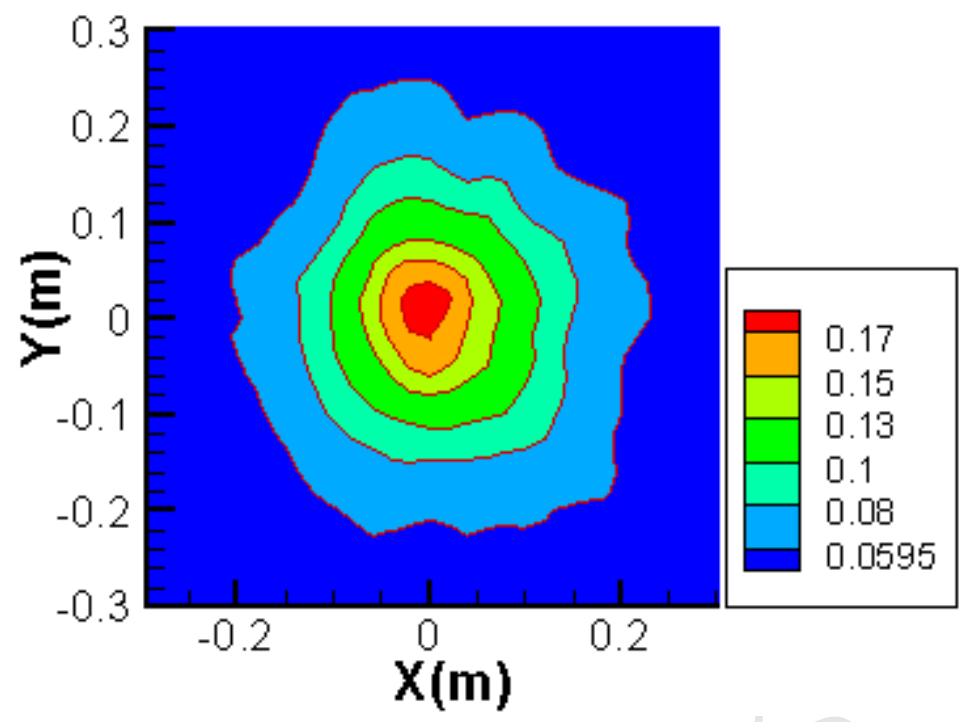

Figure 8. Predicted 2D counts of average mixture fraction in under the ceiling for the case: $\mathrm{HRR}=50 \mathrm{~kW}$ and $\mathrm{H}=0.3 \mathrm{~m}$. The minimum value in the figure corresponds to the stoichiometric mixture fraction of propane, 0.0595 . 

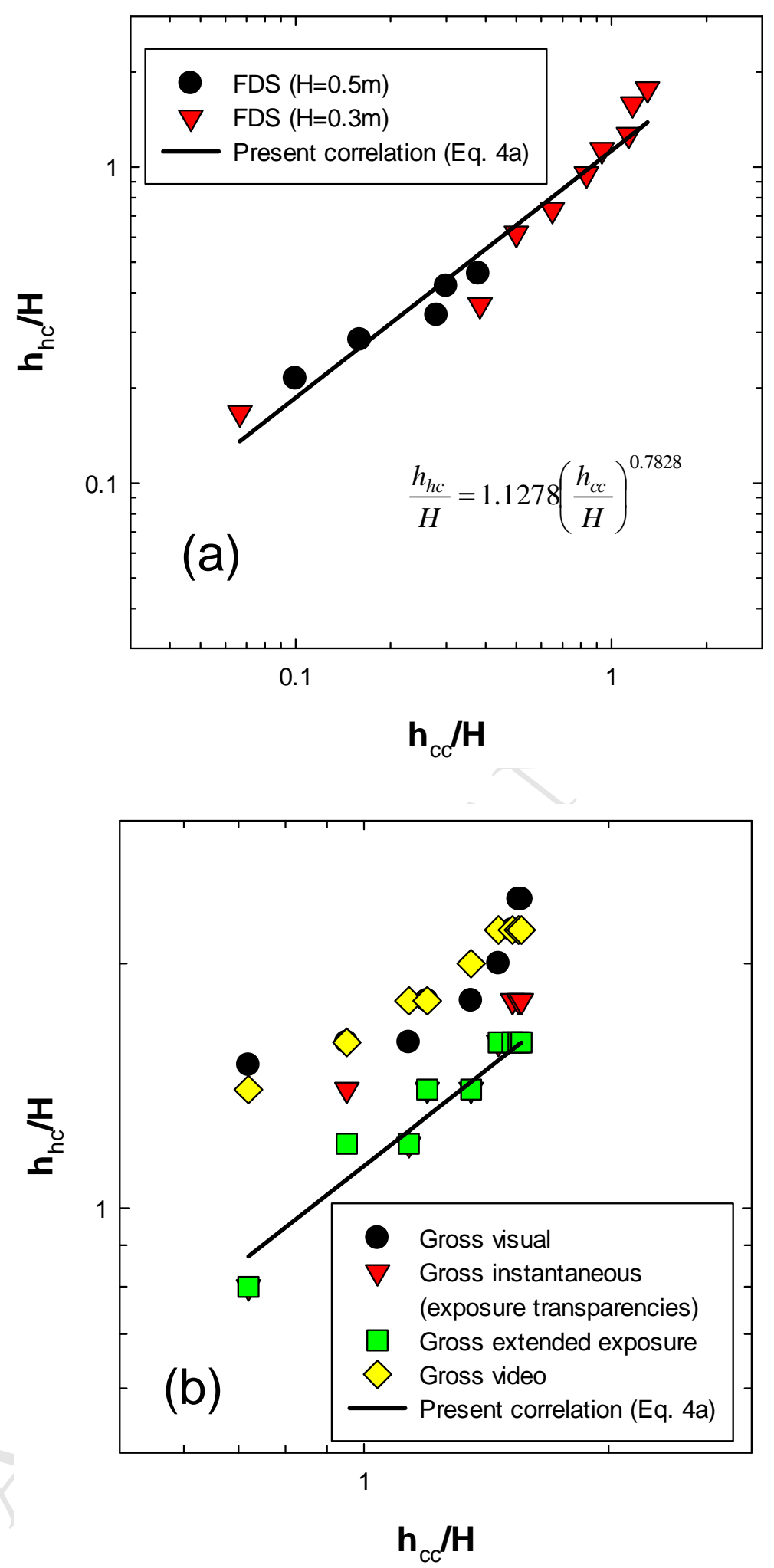

Figure 9. (a) Predicted normalized continuous horizontal flame extent, $h_{h c} / H$, against normalized continuous cut-off height, $h_{c c} / H, \quad$ and the present correlation (Eq. 4a) and (b) comparison of the present correlation with experimental data in (Gross, 1989). 


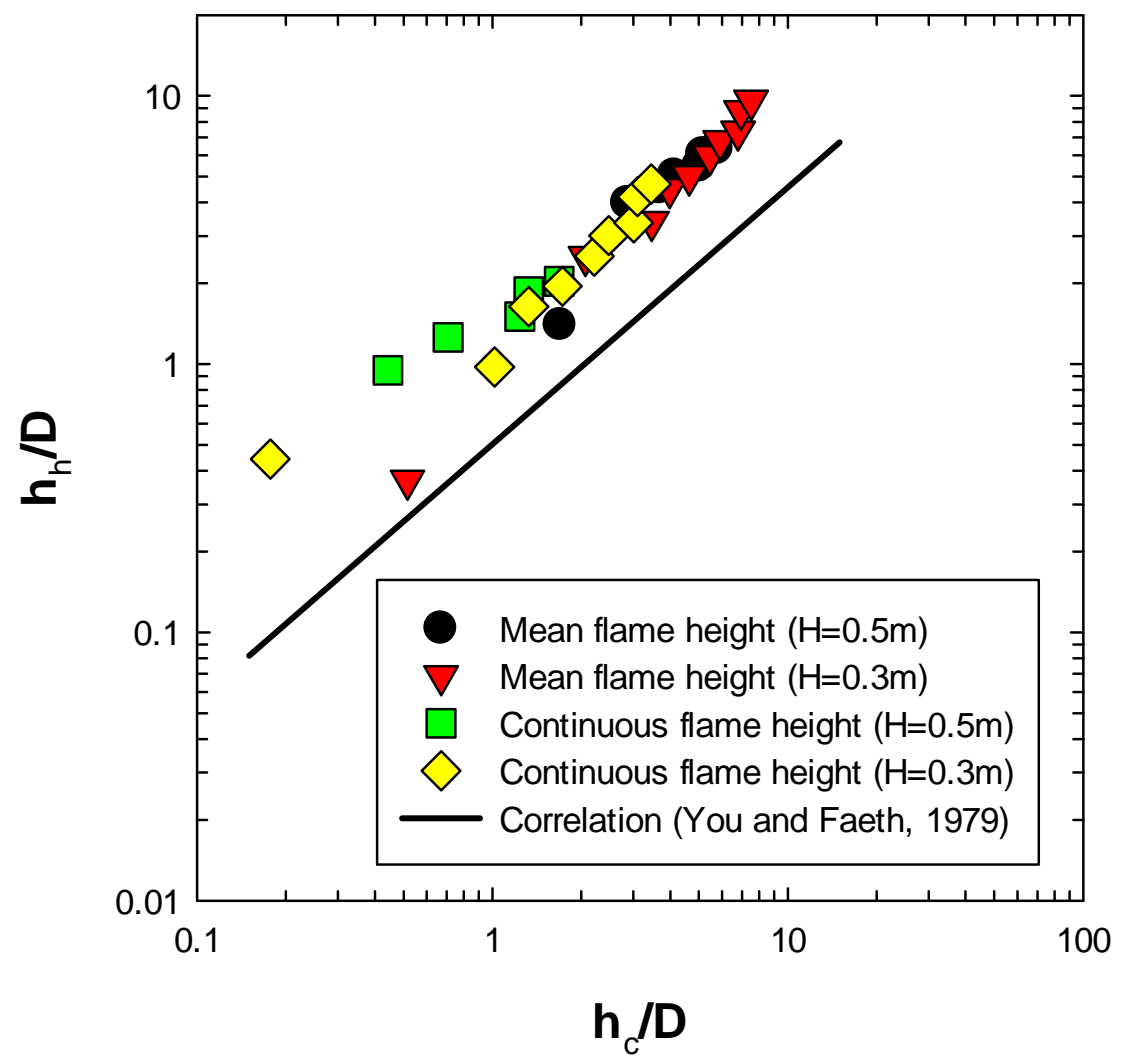

Figure 10. Comparison of predicted normalized horizontal flame length, $h_{h} / D$, against normalized cut-off flame height, $h_{c} / D$, using both mean and continuous flame heights for both ceiling heights. The correlation (You and Faeth, 1979) is calculated based on the mean flame height. 


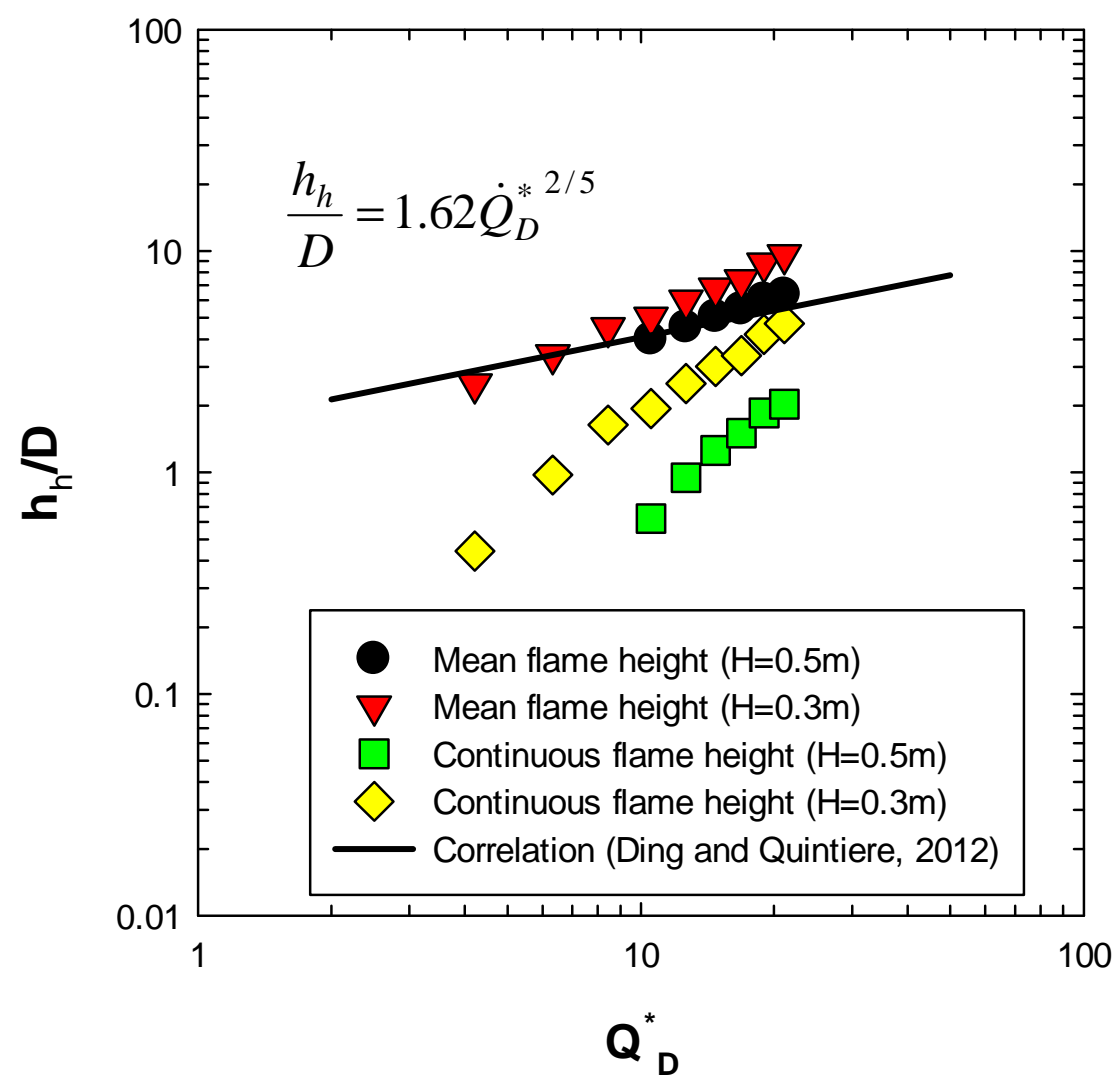

Figure 11. Comparison of predicted normalized horizontal flame length, $h_{h} / D$, against normalized heat release rate, $\dot{Q}_{D}^{*}$, using both mean and continuous flame height for both ceiling heights. The correlation (Ding and Quintiere, 2012) is calculated based on the mean flame height. 


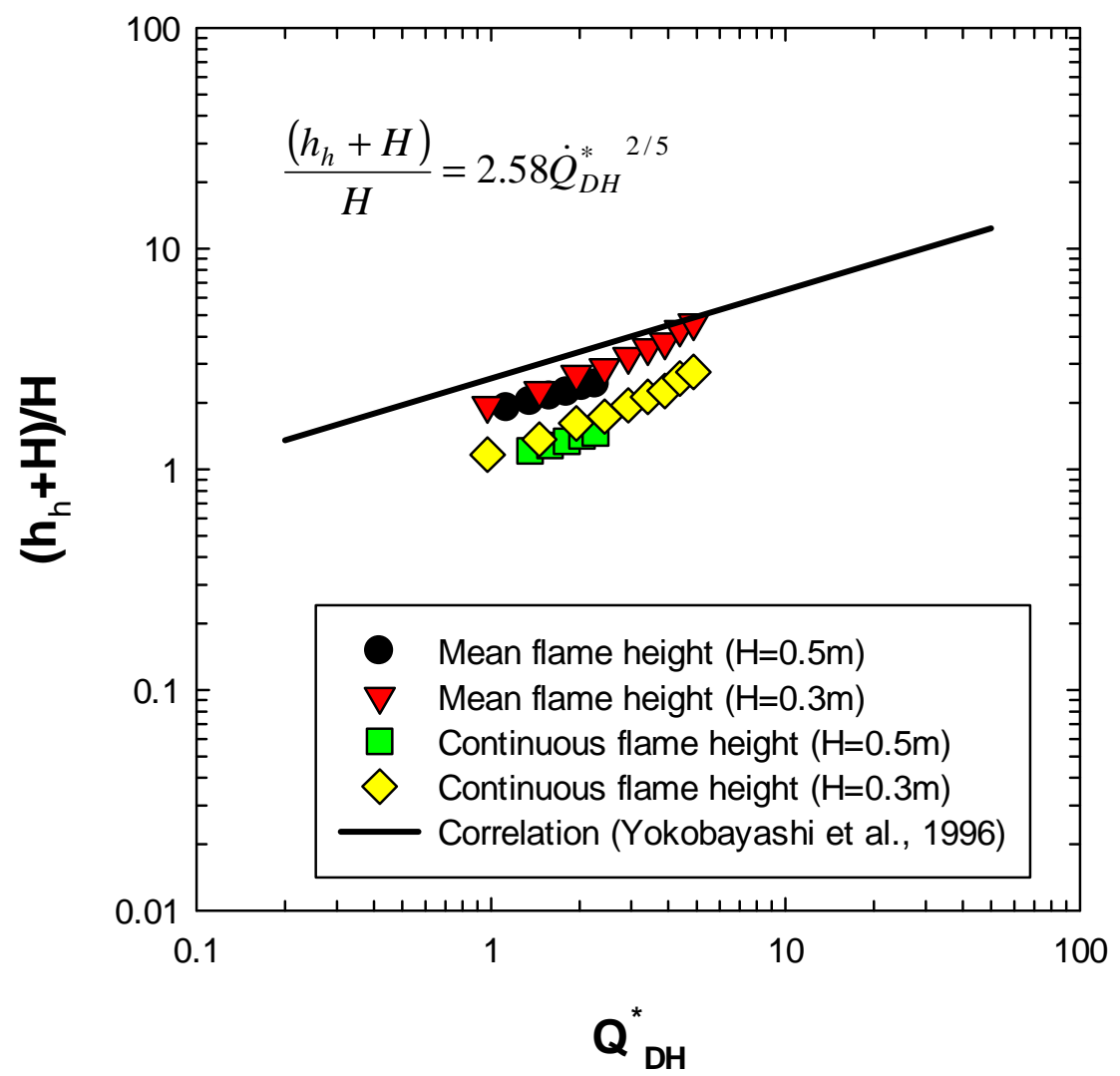

Figure 12. Comparison of predicted normalized horizontal flame length, $\left(h_{h}+H\right) / H$, against normalized heat release rate, $\dot{Q}_{D H}^{*}$, using both mean and continuous flame height for both ceiling heights. The correlation (Yokobayashi et al., 1996) is calculated based on the mean flame height. 


\section{Highlights}

- Validation of FDS 6 for pool fire simulations

- Use of stoichiometric mixture fraction for estimation of flame height and extent

- Investigation of the effects of ceiling on flame height

- Development of a new correlation for flame extent under ceiling 